\title{
Pengaruh Lingkungan Kerja Terhadap Kepuasan Kerja Dengan Motivasi Sebagai Mediasi
}

\author{
Isabella Jasmine dan Edalmen \\ Program Studi Sarjana Manajemen, Fakultas Ekonomi dan Bisnis \\ Universitas Tarumanagara, Jakarta \\ Email: isabella.115160109@stu.untar.ac.id
}

\begin{abstract}
This study aims to analyze the influence of Work Environment towards Job Satisfaction with Motivation as intervening. This study uses primary data that was collected from questionnaires distributed indirectly (through social media). The population in this study are employee of PwC Indonesia based in Jakarta in the audit division. The samples used in this study are 115 respondents in total that was collected using Slovin formula. The data was processed with Partial Least Square - Structural Equation Model using SmartPLS 3.2.7 software. Findings of this study show that Work Environment does influence Job Satisfaction with Motivation as intervening. Motivation partially intervenes the influence of Work Environments towards Job Satisfaction.
\end{abstract}

Keywords: Work Environment, Job Satisfaction, Motivation.

Abstrak: Penelitian ini bertujuan untuk menganalisis pengaruh Lingkungan Kerja terhadap Kepuasan Kerja dengan Motivasi sebagai mediasi. Penelitian ini menggunakan data primer yang dikumpulkan dari kuesioner yang didistribusikan secara tidak langsung (melalui media sosial). Populasi dalam penelitian ini adalah karyawan PwC Indonesia yang berada di Jakarta pada divisi audit. Sampel yang digunakan dalam penelitian ini berjumlah 115 responden yang didapatkan menggunakan rumus Slovin. Data diproses dengan Partial Least Square - Structural Equation Model menggunakan software SmartPLS 3.2.7. Temuan penelitian ini menunjukkan bahwa Lingkungan Kerja memang mempengaruhi Kepuasan Kerja dengan Motivasi sebagai Intervening. Motivasi memediasi secara parsial pengaruh Lingkungan Kerja terhadap Kepuasan Kerja.

Kata Kunci: Lingkungan Kerja, Kepuasan Kerja, Motivasi.

\section{LATAR BELAKANG}

Kepuasan kerja merupakan salah satu faktor yang memengaruhi produktivitas karyawan. Menurut Mangkunegara (2015) suatu perasaan yang menyokong atau tidak menyokong yang dialami oleh diri karyawan dalam bekerja adalah kepuasan kerja. Situasi kerja yang ada dalam perusahaan akan memengaruhi kepuasan kerja seorang karyawan. Kepuasan kerja yang dirasakan oleh karyawan merupakan perasaan senang atau tidak senang, nyaman atau tidak nyaman atas lingkungan kerja perusahaan tempat dimana ia bekerja. Bentuk kepuasan kerja akan tercermin dari sikap positif atau negatif yang ditunjukkan oleh karyawan.

Salah satu faktor yang memengaruhi kepuasan kerja karyawan adalah lingkungan kerja. Lingkungan kerja merupakan faktor penting bagi karyawan dalam melakukan pekerjaannya karena berkontribusi kepada kedinamisan kepuasan kerja. Robbins (2015) 
mengatakan bahwa salah satu faktor yang mendorong kepuasan kerja adalah kondisi kerja yang mendukung. Lingkungan kerja yang dimaksud adalah segala sesuatu yang ada di sekitar karyawan yang dapat memengaruhi dirinya dalam menjalankan setiap tugas atau pekerjaan yang dibebankan kepada karyawan.

Penelitian yang dilakukan oleh Sitinjak (2018), Wibowo et al. (2014), Pariwosumarto et al. (2016) dan Ariani et al. (2018) menunjukkan bahwa lingkungan kerja mempunyai pengaruh yang signifikan terhadap kepuasan kerja. Sedangkan penelitian Afiyah et al. (2017) membuktikan bahwa lingkungan kerja tidak mempunyai pengaruh signifikan terhadap kepuasan kerja.

Faktor lain yang memengaruhi kepuasan kerja karyawan adalah motivasi. Menurut Luthans (2011) proses yang dimulai dengan definisi fisiologis atau psikologis yang menggerakkan perilaku atau dorongan yang ditujukan untuk tujuan atau insentif adalah motivasi. Motivasi dijadikan dasar dan juga pemicu bagi seseorang untuk dapat mengerjakan suatu hal dengan semaksimal mungkin. Apabila seseorang tidak memiliki motivasi yang tinggi dalam dirinya sendiri untuk melakukan sesuatu, maka ia akan melakukannya dengan setengah hati dan tidak berusaha untuk memberikan yang terbaik. Dengan adanya motivasi kerja yang tinggi maka karyawan akan mencerminkan rasa tanggung jawab dan gairah kerja yang menghasilkan keinginan untuk bekerja dan melakukan pekerjaannya dengan sebaik mungkin agar tidak mengecewakan perusahaan.

Adapun penelitian dari Ariani et al. (2018), Astuti et al. (2015), Ananto et al. (2016), Arinal et al. (2017) menemukan bahwa motivasi mempunyai pengaruh yang signifikan terhadap kepuasan kerja. Sedangkan penelitian yang dilakukan oleh Afiyah et al. (2017) memiliki hasil bahwa motivasi tidak mempunyai pengaruh signifikan terhadap kepuasan kerja. Penelitian mengenai pengaruh lingkungan kerja terhadap motivasi dilakukan oleh Prakoso et al. (2014), Rezita (2014), dan Ingsiyah et al. (2019) dimana hasil penelitian menunjukkan bahwa lingkungan kerja mempunyai pengaruh signifikan terhadap kepuasan kerja.

Saat ini PwC menyediakan jasa di berbagai bidang di antaranya yaitu audit, perpajakan (perencanaan dan kepatuhan terhadap peraturan perpajakan), dan konsultasi (pemantapan kinerja, transaksi dan penggabungan usaha serta akuisisi, dan manajemen krisis dalam berbagai area spesialisasi seperti jasa konsultasi akuntansi dan aktuarial). Karyawan dihadapkan dengan tantangan untuk menjadi fleksibel saat menghadapi tumpukan beban kerja. Hal ini membuat beberapa karyawan mengeluh akan tidak adanya work-life balance akibat kesibukan yang terus mengejar dan jadwal yang sangat padat.

Walaupun budaya dan suasana kerja di PwC Indonesia bisa dibilang cenderung lebih santai dibandingkan dengan firma akuntansi lain, para karyawan harus selalu sigap beradaptasi kapan saja dan terus meningkatkan keahlian mereka agar tidak kalah dengan karyawan lainnya. Adanya beban kerja yang begitu berat, dan waktu yang tersedia terbatas, membuat karyawan PwC Indonesia merasa jenuh dengan pekerjaannya. Lingkungan kerja di PwC Indonesia yang memiliki persaingan tinggi antar karyawan untuk meningkatkan karier masing-masing membuat karyawan merasakan stress terhadap pekerjaannya. Tidak jarang karyawan harus lembur untuk menyelesaikan pekerjaannya.

Karyawan yang terus-menerus bekerja tanpa ada jeda waktu untuk beristirahat atau berlibur, akan cepat merasa lelah dan lama-kelamaan akan muak dengan pekerjaannya. Jika hal ini terjadi secara terus-menerus, maka karyawan tidak melakukan pekerjaannya dengan maksimal, bahkan bisa saja terjadi kesalahan dalam pekerjaannya yang dapat merugikan PwC Indonesia itu sendiri. Jika karyawan $\mathrm{PwC}$ Indonesia merasa tidak puas 
akan pekerjaannya, maka pekerjaan yang dimiliki akan dipandang sebagai beban dan pada akhirnya pekerjaan tersebut hanya dilakukan untuk mendapat gaji yang didapatkan setiap bulannya untuk memenuhi kebutuhan.

\section{KAJIAN TEORI}

Menurut Ivancevich, Konopaske, dan Matteson (2014) terdapat beberapa teori motivasi yang dikemukakan oleh beberapa ahli. Teori motivasi yang pertama adalah menurut Abraham Maslow, atau yang biasa dikenal dengan teori Hierarki Kebutuhan Maslow. Lima kebutuhan dasar yang dimaksud jika diurutkan dari tingkatan pertama yaitu kebutuhan fisiologis, kebutuhan akan rasa aman, kebutuhan sosial dan kasih sayang, kebutuhan penghargaan, dan kebutuhan aktualisasi diri. Selanjutnya ada teori ERG yang dikemukakan oleh Clayto Alderfer. Alderfer mengembangkan teori Hierarki Kebutuhan Maslow. Alderfer menyatakan bahwa ada tiga kelompok utama kebutuhan yaitu Existence, Relatedness, dan Growth (ERG). Existence berarti kebutuhan yang terpenuhi oleh beberapa faktor seperti makanan, udara, air, gaji, dan kondisi pekerjaan. Relatedness merupakan kebutuhan yang terpenuhi oleh hubungan sosial dan interpersonal yang berarti. Dan growth yang bisa dipenuhi dengan kreativitas yang dilakukan oleh individu dan kontribusi yang produktif. Adapun Poceratu (2018) mengatakan bahwa motivasi adalah suatu kumpulan kekuatan energik yang mengkoordinasi di dalam dan di luar diri seorang pekerja, yang mendorong usaha kerja dalam menentukan arah perilaku, tingkat usaha, intensitas, dan kegigihan. Berdasarkan pengertian motivasi di atas, dapat disimpulkan bahwa motivasi adalah keinginan individu untuk melakukan suatu pekerjaan tertentu guna mencapai tujuan yang terdorong oleh keadaan atau kondisi dalam pribadi seseorang.

Sedarmayanti (2009) membagi lingkungan kerja menjadi dua bagian, yaitu lingkungan kerja fisik dan lingkungan kerja non fisik. Semua keadaan berbentuk fisik yang terdapat di sekitar tempat kerja yang dapat memengaruhi karyawan baik secara langsung maupun tidak langsung adalah lingkungan kerja fisik. Sedangkan semua keadaan yang berkaitan dengan hubungan kerja, baik hubungan dengan atasan maupun hubungan sesama rekan kerja, atau hubungan dengan bawahan merupakan lingkungan kerja non fisik. Menurut Harianja (2015) lingkungan kerja yang kondusif dapat meningkatkan kinerja karyawan dan sebaliknya, lingkungan kerja yang tidak memadai akan dapat menurunkan kinerja karyawan. Berdasarkan pengertian tersebut, dapat disimpulkan bahwa lingkungan kerja merupakan segala sesuatu yang ada di sekitar karyawan, yang dapat memengaruhi karyawan dalam melakukan pekerjaan dan menjalankan tugas-tugasnya untuk mencapai tujuan yang diinginkan.

Menurut Hartatik (2014) apa yang membuat seseorang lebih puas terhadap pekerjaannya merupakan hal yang teori kepuasan kerja coba ungkapkan. Terdapat beberapa teori kepuasan kerja yang diungkapkan oleh beberapa ahli. Teori Perbandingan (Discrepancy Theory) dikemukakan oleh Porter yang mengatakan bahwa menghitung selisih antara apa yang seharusnya ada dengan kenyataan yang dirasakan merupakan cara untuk mengukur kepuasan kerja. Jika tidak terdapat perbedaan antara yang diinginkan dengan yang dipersepsikan pada kenyataannya maka dapat tercapai kepuasan. Sedangkan ketidakpuasan karyawan dapat tercapai apabila kenyataan yang dirasakan semakin jauh dari standar yang ditetapkan. Kepuasan kerja karyawan adalah suatu keadaan emosional baik positif maupun negatif yang memengaruhi pekerjaannya. Dapat dikatakan positif apabila semua aspek yang diinginkan terwujud sesuai harapannya, tapi dapat dikatakan 
negatif apabila semua aspek-aspek yang diinginkan terjadi tidak sesuai dengan keinginannya.

Rasa jenuh dan bosan dalam bekerja dapat dikurangi dengan adanya kesan yang nyaman akan lingkungan kerja. Kepuasan kerja yang terwujud merupakan dampak dari kenyamanan dalam bekerja. Sebaliknya, akibat fatal yang berupa menurunnya motivasi kerja karyawan itu sendiri dan menghasilkan kepuasan kerja karyawan yang berpengaruh terhadap kinerja karyawan dalam bekerja merupakan akibat dari ketidaknyamanan lingkungan kerja yang dialami oleh karyawan.

Perusahaan harus benar-benar memperhatikan lingkungan kerja untuk kepentingan seluruh karyawan. Dengan terciptanya lingkungan kerja yang nyaman dan baik, maka akan meningkatkan motivasi kerja karyawan serta perusahaan akan mendapatkan dampak yang baik. Terpenuhinya kebutuhan dan keinginan melalui kegiatan bekerja karyawan adalah salah satu arti kepuasan kerja. Salah satu faktor penting untuk memotivasi pegawai yang memiliki aneka kebutuhan primer dan sekunder sebagai manusia adalah kebutuhan. Karyawan akan merasa termotivasi jika kebutuhannya terpenuhi, dengan terpenuhinya kebutuhan karyawan maka akan timbul kepuasan kerja. Penelitian yang diakukan oleh Ananto, Rahyuda, dan Priartrini (2016) menunjukkan bahwa motivasi berpengaruh positif dan signifikan terhadap kepuasan kerja.

Berdasarkan kerangka penelitian di atas maka dapat diperoleh model penelitian sebagai berikut:

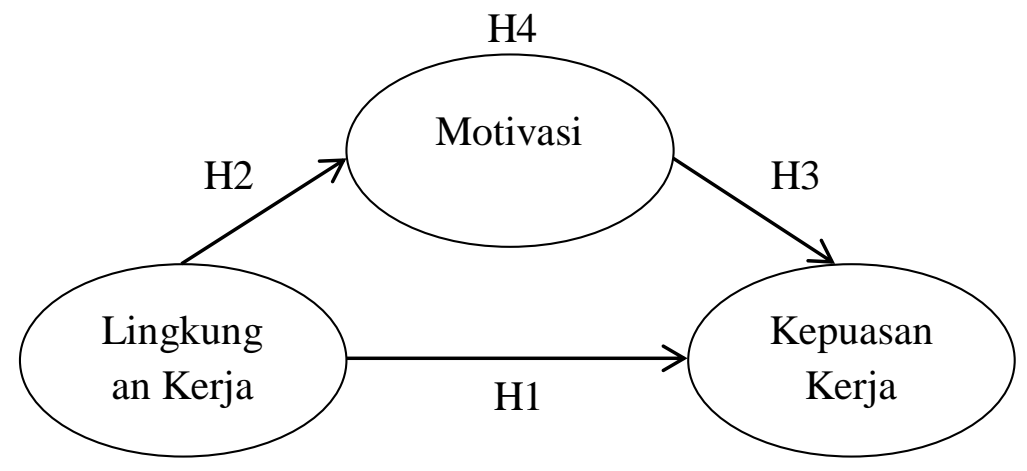

Gambar 1. Model Penelitian

Berdasarkan model penelitian diatas, hipotesis yang akan diuji dalam penelitian ini adalah sebagai berikut:

H1 : Lingkungan kerja mempunyai pengaruh yang signifikan terhadap kepuasan kerja.

H2 : Lingkungan kerja mempunyai pengaruh yang signifikan terhadap motivasi.

H3 : Motivasi mempunyai pengaruh yang signifikan terhadap kepuasan kerja

H4 : Lingkungan kerja mempunyai pengaruh yang signifikan terhadap kepuasan kerja dengan motivasi sebagai variabel mediasi.

\section{METODOLOGI}

Metode yang akan digunakan untuk memilih sampel pada penelitian ini yaitu dengan menggunakan rumus Slovin. Populasi dari penelitian ini adalah seluruh karyawan divisi audit PwC Indonesia yang berada di Jakarta sebanyak 200 karyawan. Sampel yang diperoleh menggunakan rumus Slovin sebanyak 67 sampel. Data yang digunakan dalam 
penelitian ini adalah data primer yang diperoleh dari responden melalui kuesioner online yang dibuat menggunakan Google Form. Penyebaran kuesioner dilakukan selama seminggu melalui media sosial.

Penelitian ini terdiri dari variabel independen, variabel dependen, dan variabel mediasi. Vaaariabel independen merupakan variabel prediktor atau variabel yang memengaruhi variabel dependen. Sedangkan variabel dependen adalah variabel yang dipengaruhi atau yang menjadi akibat karena adanya variabel independen. Variabel yang berperan sebagai perantara hubungan antara variabel independen dan dependen, sehingga variabel independen tidak langsung memengaruhi timbulnya atau berubahnya variabel dependen yang disebut sebagai variabel mediasi atau intervening.

Pada penelitian ini terdapat lingkungan kerja sebagai variabel independen, kepuasan kerja sebagai variabel dependen dependen, dan motivasi sebagai variabel mediasi. Masingmasing variabel memiliki 7 indikator dan diukur dengan menggunakan skala likert dengan besarnya skor berkisar antara 1-5.

Penelitian ini menggunakan metode PLS-SEM dengan menggunakan software SmartPLS versi 3.2.7. Dalam pengujian ini terdapat uji outer model dan uji inner model.

\section{HASIL ANALISIS DATA}

Penelitian ini dilakukan dengan bertahap, yakni uji awal dan uji akhir.

Pengujian Outer Model. Hasil dari pengujian outer model terdapat angka loading factor yang harus dieliminasi karena tidak memenuhi syarat. Adapun indikator yang dieliminasi adalah indikator LK4 dan M3. Berikut gambar pengujian outer model setelah dilakukan eliminasi dua indikator tersebut:

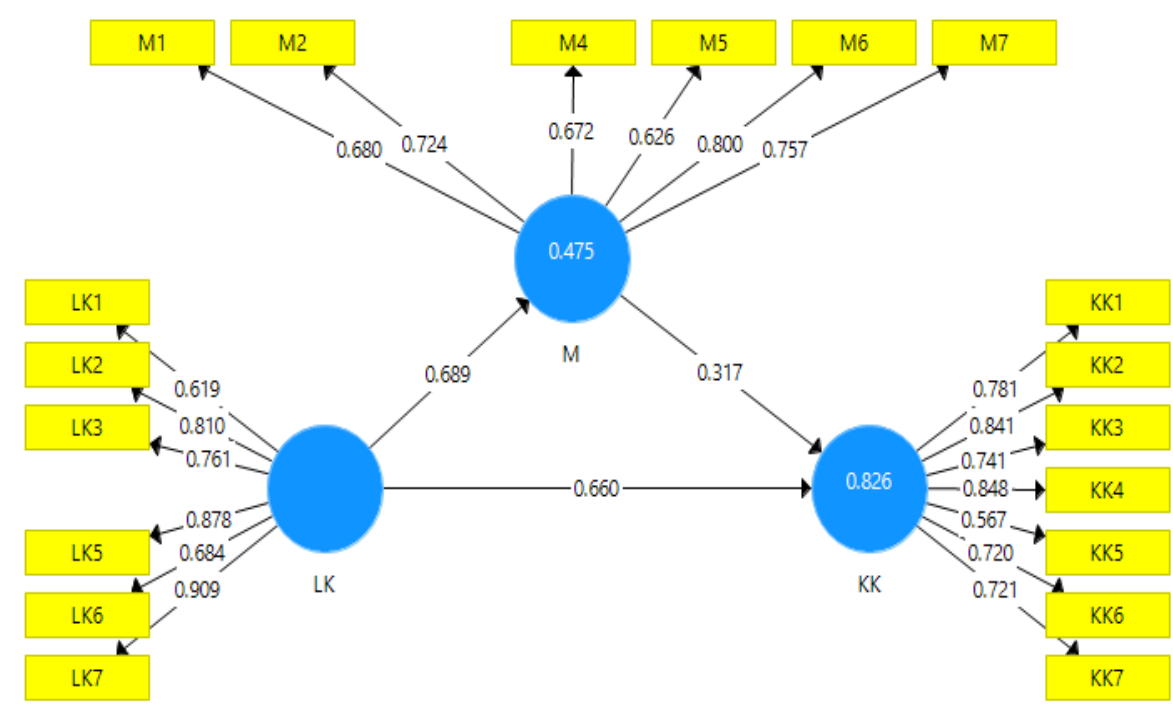

Gambar 2. Hasil Hasil Analisis PLS Algorithm 
Tabel 1. Hasil Analisis Average Variance Extracted

\begin{tabular}{|c|c|}
\hline Variabel & Average Variance Extracted (AVE) \\
\hline Lingkungan Kerja & 0,614 \\
\hline Motivasi & 0,507 \\
\hline Kepuasan Kerja & 0,563 \\
\hline
\end{tabular}

Berdasarkan tabel 1 seluruh varibael telah memenuhi kriteria Average Variance Extracted sehingga dapat disimpulkan bahwa indikator pada penelitian ini valid.

Tabel 2. Hasil Cross Loading

\begin{tabular}{|c|c|c|c|}
\hline Kode Indikator & Lingkungan Kerja & Motivasi & $\begin{array}{c}\text { Kepuasan } \\
\text { Kerja }\end{array}$ \\
\hline LK1 & $\mathbf{0 . 6 1 9}$ & 0.430 & 0.512 \\
\hline LK2 & $\mathbf{0 . 8 1 0}$ & 0.537 & 0.638 \\
\hline LK3 & $\mathbf{0 . 7 6 1}$ & 0.460 & 0.606 \\
\hline LK5 & $\mathbf{0 . 8 7 8}$ & 0.606 & 0.842 \\
\hline LK6 & $\mathbf{0 . 6 8 4}$ & 0.543 & 0.622 \\
\hline LK7 & $\mathbf{0 . 9 0 9}$ & 0.632 & 0.840 \\
\hline M1 & 0.533 & $\mathbf{0 . 6 8 0}$ & 0.584 \\
\hline M2 & 0.412 & $\mathbf{0 . 7 2 4}$ & 0.473 \\
\hline M4 & 0.486 & $\mathbf{0 . 6 7 2}$ & 0.584 \\
\hline M5 & 0.350 & $\mathbf{0 . 6 2 6}$ & 0.439 \\
\hline M6 & 0.564 & $\mathbf{0 . 8 0 0}$ & 0.620 \\
\hline M7 & 0.549 & $\mathbf{0 . 7 5 7}$ & 0.561 \\
\hline KK1 & 0.693 & 0.578 & $\mathbf{0 . 7 8 1}$ \\
\hline KK2 & 0.789 & 0.586 & $\mathbf{0 . 8 4 1}$ \\
\hline KK3 & 0.596 & 0.573 & $\mathbf{0 . 7 4 1}$ \\
\hline KK4 & 0.806 & 0.640 & $\mathbf{0 . 8 4 8}$ \\
\hline KK5 & 0.449 & 0.459 & $\mathbf{0 . 5 6 7}$ \\
\hline KK6 & 0.567 & 0.620 & $\mathbf{0 . 7 2 0}$ \\
\hline KK7 & 0.646 & 0.600 & $\mathbf{0 . 7 2 1}$ \\
\hline
\end{tabular}

Berdasarkan tabel 2 seluruh indikator telah memenuhi kriteria cross loading sehingga dapat disimpulkan indikator pada penelitian ini valid.

Tabel 3. Hasil Uji Reliabilitas

\begin{tabular}{|c|c|c|}
\hline Variabel & $\begin{array}{c}\text { Composite } \\
\text { Reliability }\end{array}$ & Cronbach's Alpha \\
\hline Lingkungan Kerja & 0,904 & 0,870 \\
\hline Motivasi & 0,860 & 0,804 \\
\hline Kepuasan Kerja & 0,899 & 0,868 \\
\hline
\end{tabular}


Seluruh indikator dalam penelitian ini memenuhi kriteria reliabilitas instrumen karena composite reliability $\geq 0,6$ dan cronbach's alpha $\geq 0,6$.

Pengujian Inner Model

Coefficient of Determination $\left(\mathbf{R}^{2}\right)$. Nilai dari koefisien determinasi (coefficient of determination; $\mathrm{R}^{2}$ ) menunjukkan besarnya kontribusi dari variabel lingkungan kerja terhadap kepuasan kerja, lingkungan kerja terhadap motivasi, dan motivasi terhadap lingkungan kerja.

Tabel 4. Hasil Uji $\mathrm{R}^{2}$

\begin{tabular}{|c|c|}
\hline Variabel & $\mathbf{R}^{\mathbf{2}}$ \\
\hline Motivasi & 0,826 \\
\hline Kepuasan Kerja & 0,475 \\
\hline
\end{tabular}

Dari tabel 3 dapat terlihat bahwa variabel Motivasi dapat dijelaskan sebesar 82,60\% oleh variabel Lingkungan Kerja, sedangkan sisanya 17,40\% dapat dijelaskan oleh variabel lain di luar variabel pada penelitian ini. Sedangkan variabel Kepuasan Kerja dapat dijelaskan sebesar 47,50\% oleh variabel Lingkungan Kerja dan Motivasi, sedangkan sisanya $52,50 \%$ dapat dijelaskan oleh variabel lain selain dari variabel yang terdapat pada penelitian ini.

Predictive Relevance $\left(\mathbf{Q}^{2}\right)$. Uji predictive relevance dilakukan dengan tujuan untuk mengetahui bagaimana konstuk dari variabel-variabel yang terdapat dalam penelitian dapat digunakan untuk mengukur model penelitian yang telah terbentuk sebelumnya. Nilai $\mathrm{Q}^{2}$ didapatkan melalui metode blindfolding. Hasil dari pengujian predictive relevance disajikan dalam tabel di bawah ini.

Tabel 5. Hasil Uji $Q^{2}$.

\begin{tabular}{|c|c|}
\hline Variabel & $\mathbf{Q}^{\mathbf{2}}$ \\
\hline Motivasi & 0,215 \\
\hline Kepuasan Kerja & 0,424 \\
\hline
\end{tabular}

Berdasarkan hasil nilai $\mathrm{Q}^{2}$ yang diperoleh tersebut, dapat dinyatakan bahwa untuk mengukur model penelitian ini konstruk-konstruk tersebut dapat digunakan karena nilai $\mathrm{Q}^{2}$ lebih dari nol.

Effect Sizes $\left(\mathbf{f}^{\mathbf{2}}\right)$. Untuk mengetahui bagaimana variabel prediktor (variabel independen dan variabel mediasi) memiliki efek pada model struktural merupakan tujuan dilakukannya pengujian effect sizes $\left(\mathrm{f}^{2}\right)$. Vinzi et al. (2010) menggolongkan efek variabel prediktor menjadi tiga kategori yaitu 0,02 (pengaruh variabel laten eksogen lemah), 0,15 (pengaruh variabel laten eksogen moderat), dan 0,35 (pengaruh variabel laten eksogen kuat). 
Tabel 6. Hasil Effect Sizes.

\begin{tabular}{|c|c|c|}
\hline Variabel & Motivasi & Kepuasan Kerja \\
\hline Lingkungan Kerja & 0,905 & 1,313 \\
\hline Motivasi & & 0,304 \\
\hline
\end{tabular}

Variabel lingkungan kerja memiliki efek perubahan yang kuat sebesar 0,905 terhadap variabel motivasi. Lingkungan kerja juga mempunyai efek perubahan yang kuat sebesar 1,313 terhadap kepuasan kerja. Sedangkan motivasi memiliki efek perubahan yang moderat sebesar 0,304 terhadap kepuasan kerja.

Path Coefficients. Tujuan dari dilakukannya analisis path coefficients yakni untuk menunjukkan keterkaitan antara satu variabel dengan variabel lainnya pada penelitian. Nilai path coefficients didapatkan melalui metode bootstrapping. Tabel 7 menunjukkan hasil bootstrapping penelitian ini yang dilakukan menggunakan SmartPLS 3.2.7.

Tabel 7. Hasil Path Coefficients

\begin{tabular}{|c|c|c|c|c|c|c|}
\hline \multirow{2}{*}{ Variabel } & \multicolumn{3}{|c|}{ Motivasi } & \multicolumn{3}{c|}{ Kepuasan Kerja } \\
\cline { 2 - 7 } & $\begin{array}{c}\text { Path } \\
\text { Coefficients }\end{array}$ & $\begin{array}{c}\text { t- } \\
\text { statistics }\end{array}$ & $\begin{array}{c}\text { p- } \\
\text { values }\end{array}$ & $\begin{array}{c}\text { Path } \\
\text { Coefficients }\end{array}$ & $\begin{array}{c}\text { t- } \\
\text { statistics }\end{array}$ & $\begin{array}{c}\text { p- } \\
\text { values }\end{array}$ \\
\hline $\begin{array}{c}\text { Lingkungan } \\
\text { Kerja }\end{array}$ & 0,689 & 13,279 & 0,000 & 0,660 & 9,739 & 0,000 \\
\hline Motivasi & & & & 0,317 & 3,848 & 0,000 \\
\hline
\end{tabular}

Variabel lingkungan kerja merupakan pengaruh positif terhadap motivasi dengan nilai sebesar 0,689. Sedangkan variabel lingkungan kerja juga berperan sebagai pengaruh positif terhadap kepuasan kerja dengan nilai sebesar 0,660. Adapun variabel motivasi mempunyai pengaruh positif terhadap variabel kepuasan kerja dengan nilai sebesar 0,317.

Hasil Pengujian Hipotesis. Nilai t-statistics ditujukan untuk menguji hipotesis penelitian, dimana hipotesis penelitian dapat diterima apabila nilai t-statistics variabel diatas 1,96 dan p-value kurang dari 0,05 .

a. Berdasarkan pengujian variabel lingkungan kerja terhadap kepuasan kerja, nilai $t$ statisctic sebesar 9,739 lebih besar dari 1,96 sedangkan p-value sebesar 0,000 kurang dari 0,05. Dengan demikian, dapat dibuktikan bahwa lingkungan kerja mempunyai pengaruh yang signifikan terhadap kepuasan kerja.

b. Berdasarkan pengujian variabel lingkungan kerja terhadap kepuasan kerja, nilai $t$ statisctic sebesar 13,279 lebih besar dari 1,96 sedangkan p-value sebesar 0,000 lebih kecil dari 0,05. Demikian dapat dibuktikan bahwa lingkungan kerja mempunyai pengaruh yang signifikan terhadap motivasi.

c. Berdasarkan pengujian variabel motivasi terhadap kepuasan kerja, nilai t-statisctic sebesar 3,848 lebih besar dari 1,96 sedangkan $p$-value sebesar 0,000 lebih kecil dari 0,05 . Dengan demikian, dapat dibuktikan bahwa motivasi mempunyai pengaruh yang signifikan terhadap kepuasan kerja. 
d. Berdasarkan pengujian dari ketiga hipotesis di atas, maka hipotesis keempat dapat dibuktikan bahwa lingkungan kerja mempunyai pengaruh yang signifikan terhadap kepuasan kerja dengan motivasi sebagai variabel mediasi.

\section{DISKUSI}

Berdasarkan hasil penelitian ini, variabel lingkungan kerja mempunyai pengaruh yang signifikan terhadap kepuasan kerja. Adanya sumber udara (sirkulasi udara) yang baik serta terjalinnya komunikasi yang lancar antara bawahan ke atasan dapat meningkatkan kepuasan kerja karyawan. Hal ini sejalan dengan penelitian yang dilakukan oleh Sitinjak (2018), Wibowo et al. (2014), Pariwosumarto et al. (2016) dan Ariani et al. (2018) yang menyatakan bahwa lingkungan kerja memiliki pengaruh yang signifikan terhadap kepuasan kerja. Penelitian ini juga memiliki hasil yang berbeda dengan penelitian yang dilakukan oleh Afiyah et al. (2017) dimana lingkungan kerja berpengaruh tidak signifikan terhadap kepuasan kerja karyawan.

Variabel lingkungan kerja mempunyai pengaruh yang signifikan terhadap motivasi. Dengan adanya sirkulasi udara yang baik serta komunikasi yang baik antara bawahan ke atasan dapat menimbulkan motivasi bagi karyawan untuk melakukan pekerjaannya dengan baik. Hasil penelitian ini sama dengan penelitian-penelitian sebelumnya yang telah dilakukan oleh Prakoso et al. (2014), Rezita (2014), dan Ingsiyah et al. (2019) dimana hasil penelitian menunjukkan bahwa lingkungan kerja mempunyai pengaruh signifikan terhadap kepuasan kerja.

Variabel motivasi mempunyai pengaruh yang signifikan terhadap kepuasan kerja. Karyawan yang diberi pekerjaan baru serta kesempatan untuk berkembang dalam pekerjaannya dapat memotivasi karyawan dalam melakukan pekerjaannya dan menghasilkan rasa puas pada pekerjaannya. Hal ini sesuai dengan penelitian yang dilakukan oleh Ariani et al. (2018), Astuti et al. (2015), Ananto et al. (2016), Arinal et al. (2017) bahwa motivasi mempunyai pengaruh yang signifikan terhadap kepuasan kerja. Sedangkan hasil penelitian ini memiliki hasil berbeda dengan penelitian yang dilakukan oleh Afiyah et al. (2017) memiliki hasil bahwa motivasi tidak mempunyai pengaruh signifikan terhadap kepuasan kerja.

\section{PENUTUP}

Penelitian ini mengambil sampel 115 responden yang bekerja sebagai karyawan divisi audit di PwC Indonesia yang berada di Jakarta. Dalam menganalisis data, penulis menggunakan Structural Equation Model Partial Least Square (SEM-PLS) melalui perangkat lunak SmartPLS v.3.2.7. Berdasarkan hasil penelitian ini, lingkungan kerja mempunyai pengaruh yang signifikan terhadap kepuasan kerja. Lingkungan kerja juga mempunyai pengaruh yang signifikan terhadap motivasi. Motivasi mempunyai pengaruh yang signifikan terhadap kepuasan kerja. Dan lingkungan kerja mempunyai pengaruh yang signifikan terhadap kepuasan kerja dengan motivasi sebagai mediasi secara parsial.

Terkait dengan hasil yang diperoleh dengan segala keterbatasannya, maka saran yang dapat diberikan oleh penulis adalah agar penelitian selanjutnya meningkatkan jumlah sampel dan memperluas jangkauan pengambilan sampel agar dapat memperbaiki serta memperkuat penelitian-penelitian sebelumnya dengan adanya keragaman dalam karakteristik dari sampel penelitian dan mengikutsertakan variabel lainnya dalam 
penelitian seperti kompensasi, budaya organisasi, turnover intention, organizational citizenship behaviour, dan variabel lainnya. Bagi Kantor Akuntan Publik (khususnya PwC Indonesia yang berada di Jakarta pada divisi audit), disarankan untuk memperbaiki suhu udara di kantor supaya kondisi kerja menjadi lebih nyaman bagi karyawan. Adanya kondisi kerja yang baik dapat meningkatkan kepuasan karyawan terhadap pekerjaannya dan dapat memberi motivasi bagi karyawan untuk bekerja karena kondisi kerja sesuai dengan harapan. Selain itu, karyawan sebaiknya diberi tanggung jawab baru yang tidak monoton serta kesempatan untuk berkembang sehingga karyawan memiliki semangat untuk bekerja lebih baik dan kariernya pun bisa meningkat.

\section{DAFTAR PUSTAKA}

Afiyah, S., Djaelani, A.Q., Priyono, A.A. (2017). Pengaruh Kompensasi, Lingkungan Kerja, dan Motivasi Terhadap Kepuasan Kerja Karyawan (Studi Kasus pada Badan Pertanahan Nasional Kabupaten Malang). Jurnal Ilmiah Riset Manajemen (Ejrm), 6(2), 328-341.

Ananto, S., Rahyuda, I.K., Priartrini, P.S. (2016). Pengaruh Motivasi Terhadap Kepuasan Kerja dan Intensi Keluar pada Asisten Kursus Metode Kumon di Bali dan Lombok. E-Jurnal Ekonomi dan Bisnis Universitas Udayana, 5(9), 3057-3085.

Ariani, Hj. M., Assarofa, A. (2018). Pengaruh Motivasi, Disiplin, dan Lingkungan Kerja Terhadap Kepuasan Kerja Karyawan: Studi Kasus pada PT. Palma Plantasindo di Desa Sunge Batu Kecamatan Pasir Belengkong Kabupaten Paser. Conference on Management and Behavioral Studies Universitas Tarumanagara, 68-77.

Arinal, V., Rahayu, A.T. (2017). Pengaruh Motivasi dan Kompensasi Terhadap Kepuasan Kerja Dosen di Sekolah Tinggi Ilmu Komputer Cipta Karya Informatika. Jurnal CKI On SPoT, 10(1), 1-10.

Astuti, H.D., Iskandar, D. (2015). Pengaruh Motivasi Terhadap Kepuasan Kerja Karyawan Studi Kasus pada PT. Chitose Internasional Tbk. E-Proceeding of Management, 2(2), 1232-1238.

Harianja, B. (2015). Pengaruh Lingkungan Kerja Terhadap Kepuasan Kerja Karyawan Studi Kasus pada Karyawan bagian Departemen Finishing di PT. Riau Andalan Kertas Kab. Pelalawan Provinsi Riau. Jurnal Online Mahasiswa (JOM) Universitas Riau, 2(2), 1-8.

Hartatik, I.P. 2014. Praktis Mengembangkan SDM. Yokyakarta: Laksana.

Ingsiyah, H., Haribowo, P., Nurkhayati, I. (2019). Pengaruh Lingkungan Kerja Terhadap Motivasi Kerja Karyawan pada PT. Pupuk Sriwidjaja Palembang, PUSRI Pemasaran Daerah (PPD) Jawa Tengah. Jurnal Politeknik Negeri Semarang (Polines), 20(1), 83 91.

Ivancevich, J.M., Konopaske, R., Matteson M.T. (2014). Organizational Behavior \& Management. 10th ed. New York: McGraw-Hill Education.

Luthans, F. (2011). Perilaku Organisasi. Edisi Sepuluh. Yogyakarta: ANDI.

Mangkunegara, A.P. (2015). Manajemen Sumber Daya Manusia Perusahaan. Bandung: PT. Remaja Rosdakarya.

Pawirosumarto, S., Sarjana P.K., Gunawan, R. (2016). The Effect of Work Environment, Leadership Style, and Organizational Culture towards Job Satisfaction and Its Implication towards Employee Performance in Parador Hotels and Resorts Indonesia. International Journal of Law and Management, 59 (6), 1337-1358. 
Poceratu, I.Ch. (2018). Pengaruh Motivasi Kerja Terhadap Kepuasan Kerja Pegawai Lembaga Pembinaan Khusus Anak (LPKA) Klas IIA Ambon Dalam Perspektif Kristiani. Jurnal Fakultas Teknik Universitas Pattimura, 163-167.

Prakoso, R.D., Astuti, E.S., Ruhana, I. (2014). Pengaruh Lingkungan Kerja Terhadap Motivasi Kerja dan Kinerja Karyawan pada Karyawan PT. AXA Financial Indonesia Cabang Malang. Jurnal Administrasi Bisnis (JAB), 14(2), 1-10.

Rezita, R. (2014). Pengaruh Lingkungan Kerja terhadap Motivasi Kerja Karyawan di Bank Jatim Cabang Utama Surabaya. Jurnal Administrasi Perkantoran (JAP), 2(2), 1-15.

Robbins, Stephen P. (2015). Perilaku Organisasi Edisi ke Sepuluh. Jakarta: Salemba Empat.

Sedarmayanti. (2009). Sumber Daya Manusia dan Produktivitas Kerja. Bandung: Mandar Maju.

Sitinjak, L.N. (2018). Pengaruh Lingkungan Kerja Terhadap Kepuasan Kerja Karyawan Studi Kasus pada Karyawan PT. Mitra Pinasthika Musthika Rent Tangerang Selatan. Jurnal Administrasi Bisnis (JAB), 60(2), 162-168.

Vinzi, V. E., Chin, W. W., Henseler, J., \& Wang, H. (2010). Handbook of Partial Least Squares. Berlin: Springer.

Wibowo, M., Musadieq, M.A., Nurtjahjono, G.E. (2014). Pengaruh Lingkungan Kerja Terhadap Kepuasan Kerja Karyawan pada Karyawan PT. Telekomunikasi Indonesia Tbk. Kandatel Malang. Jurnal Administrasi Bisnis (JAB), 16(1), 1-9. 